\title{
Health-Promoting Effects of a Job Creation Project for the Elderly: The Case of Korea
}

\section{Suk-Won Lee ${ }^{1}$ and Jae-Young Lim ${ }^{*}$}

${ }^{1}$ Graduate School of Public Administration, Seoul National University, Gwanak-ro, Gwanak-gu, Seoul, South Korea ${ }^{2}$ Department of Food and Resource Economics, Korea University, Anam-dong, Seongbuk-Gu, Seoul, South Korea

\begin{abstract}
Objectives: This paper aims to empirically examine the health-promoting effects of a Job Creation Project for the Elderly.

Methods: The study employs the database combining the 2, 808-person data of Survey on the Participants of 2007 Project and the data of the same people's annual medical records between 2001 and 2007. In order to avoid the possibility of overestimation, this paper adopts the Cohort Sequential Design to control problems possibly caused by participation time gaps as well as maturation effects and spurious causal effects.
\end{abstract}

Results: This study finds the participants reduced their annual medical costs by about $\$ 188$ and no significant difference in terms of the amounts of medical care use was found.

Discussion: The decrease in medical expenditure with no change in the amounts of medical service use implies that participants might have less serious diseases, which cost less because the participants' health status becomes improved.

Keywords: Job Creation Project for the Elderly; Medical cost reduction; Healthy Worker Effect (HWE); Cohort Sequential Design

\section{Introduction}

Korea has become an "aged society" with the elderly population (persons 65 years old and over) accounting for $11 \%$ of the total as of 2011. Furthermore, the proportion of the old is predicted to increase to $14.4 \%$ in 2019 and $20 \%$ in 2026, driving Korea into a "super aged society" (Korean Statistical Information Service Database, accessed on March 8, 2012). This rapid aging trend is expected to have a significant influence on various economic quantities and characteristics such as economic growth, capital and labor markets, industrial structures and especially national finance in terms of both revenue and expenditure. Government revenues would shrink as tax and nontax revenues and social security contributions decrease due to the decline in the workingage population and slower economic growth. On the other hand, agerelated government expenditures would greatly increase on account of the growing number of pension recipients along with rising medical and other social welfare costs for the elderly. As the aged population holds far higher prevalence rates than the average and is likely to include more chronic disease patients, medical costs per elderly person are three to five times larger than those of the non-aged [1]. Thus, the total medical costs increased by the rise in the elderly population will exceed what would normally be caused by simple population growth.

An effective strategy to prepare for the expected financial burden of the Government is to delay the retirement age or to encourage reemployment of elderly workers. Employing the old is desirable in that the problem of working-age population shortage in an aged society would be alleviated and government expenditures related to social security would be reduced because more elderly people would be able to support themselves (Employing the old can also extend the period for paying pension contributions and delays the commencement of the pensionable tenure, which would in turn decrease the national financial burden).

As part of this strategy, since 2004 the Korean Government has been implementing the "Job Creation Project for the Elderly", a welfare project that provides job opportunities for persons 65 years or older.
Besides providing economic stability by offering jobs to the old, the project is expected to produce positive side effects in that the elderly can boost their self-esteem through social activities and enjoy better access to various resources to stay healthy. Indeed, employing the old could possibly improve their health status and in turn reduce their medical costs.

This issue, whether or not the fact that one has a job - not only for the aged but also for the younger generations can have an influence on one's health status, has been actively discussed throughout much sociological literature. The previous studies mostly support the claim that there is a positive relationship between employment and health status [2]. This positive relationship is referred to as the "Healthy Worker Effect (HWE)" in occupational epidemiology. While largely accepted by academics, however, HWE is regarded as a concept which is not well defined and also not rigorously proven [3]. Moreover, HWE is often viewed along with selection bias. In other words, according to Baillargeon and Wilkinson [4], the reason why employed elders show higher health status is that i) it is likely that the healthier the elders are, the higher probability of being employed they have and ii) healthier people are also likely to keep their jobs longer than otherwise. Baillargeon and Wilkinson term the first effect the "Healthy Hire Effect (HHE)" and the second effect the "Healthy Survivor Effect (HSE)". If such selection bias exists, it is hardly possible to correctly verify the causality between labor and health status by simple correlation analysis

*Corresponding author: Jae-Young Lim, Department of Food and Resource Economics, Korea University, Anam-dong, Seongbuk-Gu, Seoul, Korea, Tel: 82232903038; Fax: 82232903030; E-mail: jylimecon@korea.ac.kr

Received November 17, 2017; Accepted December 05, 2017; Published December 12, 2017

Citation: Lee SW, Lim JY (2017) Health-Promoting Effects of a Job Creation Project for the Elderly: The Case of Korea. Health Econ Outcome Res Open Access S1: 104. doi: 10.4172/2471-268x.1000.S1-104

Copyright: $\odot 2017$ Lee SW, et al. This is an open-access article distributed unde the terms of the Creative Commons Attribution License, which permits unrestricted use, distribution, and reproduction in any medium, provided the original author and source are credited. 
because there might be reverse causality such that individual health status might influence his/her job status.

A number of studies have attempted to estimate this relationship, excluding the possibility of such reverse causality. Ross and Mirowsky [2] attempted to control the initial health status and the possibility of reverse causality by means of Ordinary Least Squares (OLS) and a covariance structure model, respectively. They proved that adults who are employed as full-time workers show much slower rates of decline in physical function and better self-perceived health status than otherwise. Link and Phelan [5] asserted that socio-economic status including employment could be a critical reason for illness in that access to resources for improving health depends on socio-economic position. Despite the fact that previous work has tried to empirically prove the linkage between employment and health, as Minkler [6] stated, most published references have serious problems in selecting appropriate samples and methodologies, thereby failing to reach consistent conclusions. Furthermore, most of the empirical work so far relies too much on results from surveys containing individuals' subjective reports on health status but does not deal with the incurred real health expenditure, which may help to find whether improved health indeed ends up with reduced medical costs.

Having considered such limitations, this study fills the gap in this field by conducting an investigation based on the data of actual medical costs and by using methods that can effectively control selection bias caused by HWE. This study aims to investigate whether the Job Creation Project for the Elderly has enhanced the health status of the participants and thereby reduced one's medical costs in practice.

The paper is organized as follows. In Section 2, we introduce the models that are specially constructed to exclude the possible reverse causality between employment and health promotion. Empirical results are presented in Section 3. Finally, we summarize the findings and present concluding remarks in Section 4.

\section{Research Methods}

\section{Data}

The Job Creation Project for the Elderly is considered as one of the most important welfare projects for the old in order to cope with the "aged society" in Korea. Administrated by central and local governments, the Korea Labor Force Development Institute for the Aged, or non-governmental organizations, the project provides the jobs appropriate for people 65 years of age and over, consequently intending to provide supplementary income support and to promote their health and social participation (The "elderly-appropriate jobs" provided by the Job Creation Project are one type of "social jobs" which intend to expand social participation and enable a healthy and joyful life for those who wish to work but are not able to; these social jobs are necessary for societal development and improved quality of individual life, but are often excluded in the market due to low returns (e.g. occupations in education, social welfare, environment, community development and health care fields). The project was established in 2004 based on the "Welfare Law for the Aged" (Art. 23 and Art. 45, Para. 2) legislated in 1981 and the "Basic Law on Low Fertility and Aging Society" (Art.11) enacted in May 2005. The project created 35, 127 jobs in 2004 and increased to 216,289 jobs in 2010, with an annual budget of about KRW 140 billion (or USD 0.14 billion) (Website of Korea Labor Force Development Institute for the Aged (http://www. kordi.or.kr/).

Participant selection criteria of the project are as follows: participants have to be healthy enough to manage some physical work and should be 65 years or older; sometimes the project includes people of age 60 to 64 years, depending on the programs. If there are too many applicants, people who are more in need are to be selected. Also, the beneficiaries of the "Basic Livelihood Security Law" and workers participating in other government employment projects are to be excluded. As summarized in Table 1, the project offers five different types of jobs: public interest services, instruction services, welfare services, collaborative micro-business and labor force dispatch. This paper, however, only examines the first three types including public interest, instruction and welfare services, which are fully financed by the government.

We created database combining the 2, 808-person data of 'Survey on the Participants of 2007 Job Creation Project for the Elderly' and the data of the same people's annual medical records between 2001 and 2007 obtained from the National Health Insurance Cooperation (NHIC). The survey covers information on general characteristics, socio-economic characteristics, participation status and participation results of the participants. The survey was conducted by extracting random samples of 2, 987 elderly who participated in September 2007 and $94 \%$ of the 2, 987 samples, such as 2, 808 persons, responded to the survey. Among these, 2, 547 persons were selected to be the final sample (Concerning sample selection issue, we checked the sample selection issue of the study by applying Heckman's Sample Selection Model on a basis of the data of applicants of this project. So after setting up the selection equation which might represent whether to be accepted, we calculated the inverse mills ratio and inserted it in the main equation as another explanatory variable. The result tells that the newly added inverse mills ratio is not shown to have statistically significant effect on medical cost of the elderly) as they participated in the project services of public interest, instruction and welfare in particular. The other two types of collaborative micro business start-up and labor force dispatch have different selection criterion, so this study focuses on only three types mentioned above.

On the other hand, since the National Health Insurance (NHI) system of Korea covers the whole population as a compulsory social insurance system, the NHIC provides a comprehensive database on individual medical expenditures measured from the NHI claim records. The data from the NHIC also cover the information from individual medical service records including specific contents of medical treatments such as duration of one's hospitalization and number of doctor-visit. Finally, by combining the data of the survey and the data of annual medical records from NHIC, we were able to convert the data into time-series-cross-section, or panel data, which turned out to be person-year data having approximately 20, 000 observations.

\begin{tabular}{|c|l|}
\hline Type & \multicolumn{1}{c|}{ Examples } \\
\hline Public interest service & $\begin{array}{l}\text { Managing street and natural environments, guiding } \\
\text { traffic flows and superintending parking, guiding subway } \\
\text { utilization and supporting social welfare institutions. }\end{array}$ \\
\hline Instruction service & $\begin{array}{l}\text { First to third generation instructor, elderly to elderly } \\
\text { instructor, forest and cultural properties interpreter, etc. }\end{array}$ \\
\hline Welfare service & $\begin{array}{l}\text { Care service (in home and institution), support of the } \\
\text { disadvantaged, protection of children and teenagers, } \\
\text { cultural welfare services, etc. }\end{array}$ \\
\hline $\begin{array}{c}\text { Collaborative micro- } \\
\text { business start-up }\end{array}$ & $\begin{array}{l}\text { Food manufacturing and merchandising, indigenous } \\
\text { product manufacturing and merchandising, cooperative } \\
\text { works, home-delivery services by subway, car-washing } \\
\text { and laundry, farming, etc. }\end{array}$ \\
\hline Labor force dispatch & $\begin{array}{l}\text { Exam supervisor, gas station attendant, apartment } \\
\text { guard, household helper, building maintainer, etc. }\end{array}$ \\
\hline Source: Korea Labor Force Development for the Aged (2011) \\
\hline \multicolumn{2}{|c|}{ Table 1: Types of job creation project for the elderly. } \\
\hline
\end{tabular}


Concerning data structure, the final sample of 2, 547 elderly people who all participated in the project of the year 2007 is categorized according to their initial participation year. Specifically, as shown in Table 2, the cohorts 2004 who participated in the project for the first time on 2004 , takes $7.1 \%$ of the total sample such as 181 $(=5+13+34+129)$ persons and $71.3 \%$ of them such as 129 persons continually participated in the project from 2005 to 2007. In the cohorts $2005,284(=64+220)$ persons participated for the first time on 2005 and the majority of them, such as 220 persons, participated in the project in 2006 and 2007 as well. The elderly whose initial participation year was 2006 such as the cohorts 2006 take $28.2 \%$ of the total sample, such as 718 persons and all of these also participated in 2007. Lastly, the cohorts 2007 such as 1, 364 persons accounting for 53.6\% of the total sample participated in 2007 for the first time.

\section{Strategies to estimate the effects of medical costs reduction}

The "effect" of a certain project is generally referred to as an added value generated to the corresponding participants. Then, the effect of medical costs reduction of the Job Creation Project for the Elderly could be considered as the gap between medical expenditures of the elderly who participated in the project and those of the same person which he or she might have paid if they had not participated in the project. In other words, the effect as an added value can be measured by comparing the counterfactual (or hypothetical) outcome, that is the outcome a person would gain 'if one had not participated', with the actual outcome. Hence, the key element in evaluating the health promotion effects of the Job Creation Project for the Elderly which might be measured by reduced medical costs is how to estimate the counterfactual aspects of the project.

In the U.S., which has abundant accumulated experience in evaluating welfare projects, only a randomized experiment is regarded as a "gold standard" to estimate the counterfactual and to evaluate the true effects of a certain project [7]. A randomized experiment is a method of classifying people into two groups, a treatment group and a control group, by a random mechanism similar to a lottery. Then an experiment is conducted only on the treatment group and thereafter the results are compared between the two groups. The reason why a randomized experiment is superior to other methods in eliminating selection bias is that choosing two groups randomly can guarantee identical expected values on average not only for the observable characteristics but also for the unobservable properties of the groups [8].

However, it is hard to apply the experimental evaluation methods to this project, given that the Job Creation Project for the Elderly is not based on a randomized experiment in advance. Instead, this paper intends to adopt a short-interrupted-time-series design combined with

\begin{tabular}{|c|c|c|c|c|c|c|}
\hline \multirow{2}{*}{$\begin{array}{l}\text { Cohort (Initial } \\
\text { participation } \\
\text { year) }\end{array}$} & \multicolumn{4}{|c|}{ Participation } & \multirow{2}{*}{ Frequencies } & \multirow{2}{*}{ Percentages } \\
\hline & 2004 & 2005 & 2006 & 2007 & & \\
\hline \multirow{4}{*}{2004} & $\mathrm{P}^{1)}$ & $\mathrm{N}^{2)}$ & $P$ & $\mathrm{P}$ & 5 & $0.2 \%$ \\
\hline & $\mathrm{P}$ & $\mathrm{P}$ & $\mathrm{N}$ & $\mathrm{P}$ & 13 & $0.5 \%$ \\
\hline & $\mathrm{P}$ & $\mathrm{N}$ & $\mathrm{N}$ & $\mathrm{P}$ & 34 & $1.3 \%$ \\
\hline & $\mathrm{P}$ & $P$ & $\mathrm{P}$ & $\mathrm{P}$ & 129 & $5.1 \%$ \\
\hline \multirow{2}{*}{2005} & $\mathrm{~N}$ & $\mathrm{P}$ & $\mathrm{N}$ & $\mathrm{P}$ & 64 & $2.5 \%$ \\
\hline & $\mathrm{N}$ & $P$ & $P$ & $\mathrm{P}$ & 220 & $8.6 \%$ \\
\hline 2006 & $\mathrm{~N}$ & $\mathrm{~N}$ & $\mathrm{P}$ & $P$ & 718 & $28.2 \%$ \\
\hline 2007 & $\mathrm{~N}$ & $\mathrm{~N}$ & $\mathrm{~N}$ & $\mathrm{P}$ & 1364 & $53.6 \%$ \\
\hline
\end{tabular}

Table 2: Participation years of the sample. a cohort design as the most suitable alternative, given such limitations. While a short-interrupted-time-series design is often used when one analyzes aggregate data for several periods by a time-series approach, data with relatively short periods can also be analyzed by using panel regression models as in Bloom's study [9]. Through combining short-interrupted-time-series design and cohort design in which the cohort might be classified by the sample's initial year of participation in the Job Creation Project, we were able to construct a study design which significantly enhances feasibility in estimating the health promotion effects of the project. With a mixture of cross-sectional and longitudinal design, this study design could be referred to as the Cohort Sequential Design; it is one form of a sequential design which was asserted as the most effective method by Schaie [10] (Shaie's sequential design is largely exploited in developmental psychology investigating the developmental process and studies such as Jenkins and Maslach [11], Lawrence and Blackburn [12], Clayton and Bokemeier [13] and Anderson [14], are the distinctive works using sequential design. For more information on sequential design, refer to Schaie [10] due to the following reasons.

To measure the effects of medical costs reduction, as mentioned earlier we divided the participants into four cohort groups according to the first year that people participated in the project: cohorts 2004, 2005, 2006 and 2007. Figure 1 displays the increasing trend of medical expenditure in the four cohorts as time passes (or as one gets older). As observed in Figure 1, if the intercepts of medical expenditure curves are to downwardly shift in each initial participation period, then the effect of medical costs reduction through participating in this project could be measured as $\alpha_{i}$ where $i=1,2,3,4$, which is the deviation from the extension line of the pre-participation medical expenditure cost curve (thin lines in Figure 1) to the post-participation curve (thick dark lines). Furthermore, if the slope of the curve becomes smaller (or flatter), the effect is likely to increase: $\alpha_{1} \rightarrow \alpha_{2} \rightarrow \alpha_{3} \rightarrow \alpha_{4}$ as the years go by.

In terms of Schaie's [10] sequential design, the differences in medical costs originated from when to participate in the project can be regarded as the cohort effects and the differences in medical costs caused from when to measure it as the time effects. Therefore when it comes to estimating effect of the reduced medical costs of this project, it is regarded as the summation of these effects. Specifically, if the

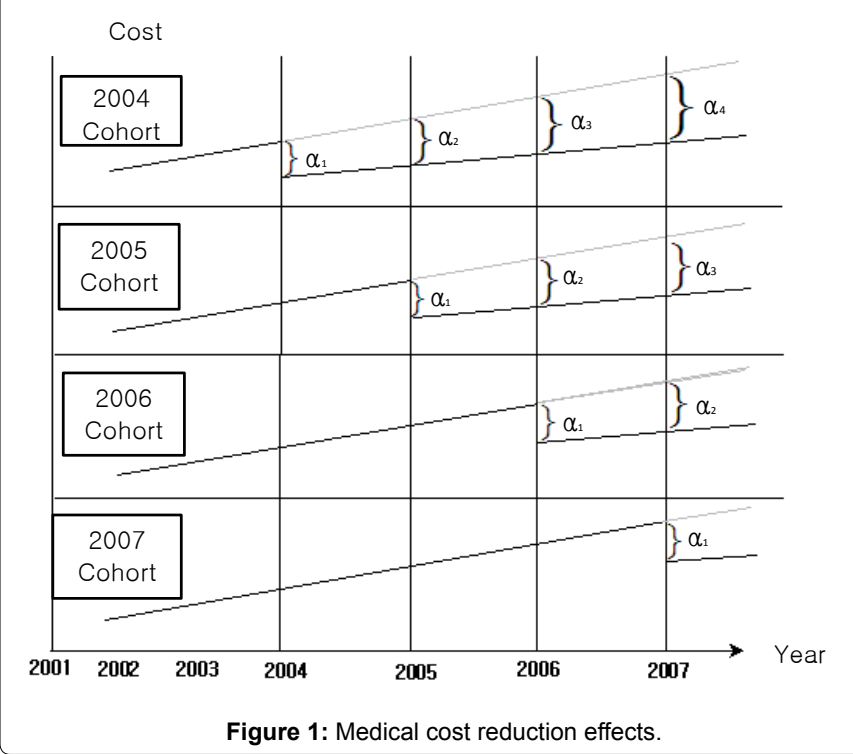


effects of medical costs reduction of the cohorts 2004 were estimated to significantly exist on 2005, this effect could have been due not only to the participation effect but also to the time effect of year 2005 itself or to the extended trend of the past such as maturation effect.

The Cohort Sequential Design has great strength in effectively controlling problems caused by participation time gaps as well as maturation effects and spurious causal effects which may obstruct appropriate estimation of the true effects of medical costs reduction. In other words, this research is designed to effectively control the characteristics of the participating elderly people, which can affect the outcomes.

Concerning the appropriateness of data used in this study, they relate to a relatively short period record since it includes only $3 \sim 6$ time periods before participation, for example 3 time periods (2001, 2002 and 2003) for cohort 2004 and 6 time periods (2001, 2002, 2003, 2004, 2005 and 2006) for cohort 2007. According to Bloom (2003), however, if the sample size is large enough and about five periods before participation in a project exist, then the model is capable of accurately estimating even with a fairly small effect size (Bloom [9] describes it as MDES (Minimum Detectable Effect Size); if the sample size is 750 and there are five time periods before participation, one can estimate the size of the effects of the first to the fourth period after being involved in a project as being as small as $0.13 \sim 0.23$. This is a "small size" of effect according to Cohen [15]. Since the number of periods before participation measured in this study satisfies Bloom's criteria, one can assume that the model holds accuracy in estimating the effects.

Although this method appears to be the good alternative to obtain validity of the estimation results among non-experimental methods, given the limited time range of the available data, the Healthy Worker Effect (HWE), that is the Healthy Hire Effect (HHE) and the Healthy Survivor Effect (HSE), may always remain as a limitation unless one conducts a random experiment. Nonetheless, this study is expected to minimize such bias for the two following reasons.

First, unique features of the comparison group allow us to safely avoid selection bias. Based on the data structure mentioned above, total sample is divided to project group and comparison group. The shadowed part of Table 2 represents "participation" on a yearly basis and those observations in the panel data comprise the project group. Meanwhile, the comparison group consists of the observations in the un-shadowed part denoting "non-participation" and the observations of all samples in the panel data from 2001 to 2003 since this project launched on 2004. This method of building up the project and comparison groups suggests that the observations constituting the project group and the comparison group are records of the same persons, which means only the observation period differs. Specifically, the comparison group in the study consists of all respondents' observations from 2001 to 2003 and the observations of those who did not participate in the Job Creation Project for the Elderly in 2004, 2005, 2006 and 2007.

However, the observations of 2001, 2002 and 2003 constitute almost the whole of the comparison group, while the share of 2004 to 2007 records is minimal. As shown in Table 2, 2, 547 elders of the total sample all participated in the project in 2007; meanwhile, among participants of cohort 2004, those who did not participate in 2005 or 2006 or either one of those years were $52(=5+13+34)$ and those who participated for the first time in 2005 (cohort 2005) but not in 2006 were 64 . Consequently, only $4.55 \%$ (116 out of 2,547 ) of the comparison group falls into the cohorts 2004 to 2007, while the rest of the samples, holding 95.45\%, belong to the observations of 2001, 2002 and 2003.
Hence, it is plausible to refer that the same person was relatively younger in the comparison group than he or she was in the project group in most cases. Therefore, some bias, if any, could exist where non-participants included in the comparison group would be healthier than in the project group. And we can think that this feature might result in the bias of opposite direction to the Healthy Hire Effect (HHE), since HHE is a bias where the participants hired in the project would be healthier than the non-participants. Thus, we can say that the effects of medical cost reduction observed in the study are somewhat safe from the selection bias of HHE which might falsely overestimate the effects. Conversely, if there is any bias, it will rather play a role in underestimating the effects.

Second, concerning the bias from the Healthy Survivor Effect (HSE), where healthy elders tend to stay in the job longer than the unhealthy, it should be kept in mind that all individuals in the samples in this study participated in the project on 2007. In other words, we are able to exclude the possibility of the comparison group including elders who retired due to their inferior health condition, since nobody retired from the project.

In sum, the special circumstance that the comparison group of the total sample is subsequently incorporated into the project group as time lapses allows us to eliminate the possibility of any bias toward overestimation but rather leads us into underestimation problems.

\section{Empirical models}

Shaie's study [10], which firstly suggested sequential design and follow-up studies conducted by Jenkins and Maslach [11], Shelly et al. [16], Lawrence and Blackburn [12], Clayton and Bokemeier [13] and Anderson [14] calculated the gap between mean values of each group to estimate cohort effects, time effects and age effects. This method, however, cannot control the effects of other factors that can influence the dependent variable (medical expenditures) or the inherent characteristics of each participant. Moreover, it does not allow us to estimate the cohort effects, time effects and age effects simultaneously, controlling of the reciprocal influences which these three effects can have. To avoid this limitation, it is desirable to construct a regression model. Equation (1) represents the first model and this estimates the effect of participating in the Job Creation Project on overall level of medical expenditures, controlling the effects caused by different cohorts, times and individual characteristics;

$$
\mathrm{Y}_{i j t}=\alpha \mathrm{P}_{i j t}+\sum_{k} \beta_{k} \mathrm{X}_{i j t k}+\gamma_{j}+\delta_{t}+\mu_{i}+\varepsilon_{i j t}
$$

where $\mathrm{Y}_{i j t}$ is the medical expenditures of $i^{\text {th }}$ participant belonging to $j^{\text {th }}$ cohort, estimated at time $t, \mathrm{P}_{i j t}$ is a vector of dummy variables representing 1 if $i^{\text {th }}$ individual belonging to $j^{\text {th }}$ cohort participated at time $t$ and 0 otherwise, $\mathrm{X}_{i j t k}$ is the vector of other control variables affecting individual medical expenditures, $\mathrm{Y}_{j}$ represents $j^{\text {th }}$ cohortspecific effect, $\delta_{t}$ represents time-specific year effect where $t$ is from 2001 to 2007, $\mu_{i}$ indicates $i^{\text {th }}$ individual-specific effect and $\varepsilon_{i t j}$ is error terms which is assumed to have normal distribution and zero mean and $\sigma_{v}^{2}$ of variance.

As mentioned before, the total samples are divided into four cohorts by initial participation year. In eqn. (1), $\mathrm{Y}_{j}$ controls these four cohort-specific effects and $\delta_{t}$ controls the effects of each time period. For instance, if the medical cost reduction effect of the participants on 2004 were estimated greater than the participant on 2005, this could have been due not only to the project's own effect but also to the time effect of year 2005 itself or the extended trend of the past (e.g. maturation effect) [17]. The term $\delta_{t}$ is used to effectively control such 
effects. Further, given that this study uses panel data, we can manage to control the unobserved individual effect as well. The term $\mu_{i}$ can be seen as the individual characteristics that may affect the medical expenditures reduction but cannot be observed directly. On the other hand, considering the possibility of autocorrelation in error terms, we assume that error terms follow AR (1) and specify them such that; $\varepsilon_{i t j}=\rho \varepsilon_{i t j-1}+v_{i t j}, v_{t} \sim \mathrm{N}\left(0, \sigma_{v}^{2}\right)$ and corr $\left(v_{\mathrm{t}}, v_{\mathrm{s}}\right)=0$ for $\forall \mathrm{t} \neq \mathrm{S}$.

The coefficient of $P_{i j t}$, , is what this study aims to examine; it estimates the effects of the medical costs reduction attributable to participating in the Job Creation Project for the Elderly. The a could be persistent as years lapse, as modeled in eqn. (1), but it could also vary as we have discussed in the previous section. Hence, in order to explore how the effects of medical cost reduction have been changed after participating in the project, we set up Model 2 by rearranging eqn (1) as the following eqn. (2) and estimate it;

$$
\mathrm{Y}_{i j t}=\sum_{l=1}^{4} \theta_{l} \mathrm{D}_{i j t l}+\sum_{k} \beta_{k} \mathrm{X}_{i j t k}+\delta_{\mathrm{t}}+\mu_{i}+\varepsilon_{i j t}
$$

Where $\mathrm{D}_{i j t}$ is the vector of dummy variables representing 1 if $l$ years have passed by after participating in the project on the basis of time $t$ and 0 otherwise for the $i^{\text {th }}$ individual belonging to the $j^{\text {th }}$ cohort $(l=1$, $2,3,4)$.

The term $l$ denotes the years passed after participating in the project; specifically, it is the gap between the report time $t$ and the initial participation time (cohort $j$ ). Although data acquisition and project participation occurred in the same year during the period 2004 to 2007 , since the data were reported at the end of the year, the data are assumed to be measured one year late. Hence, $l$ equals $t-j+1$ and has values of $1,2,3$ and 4 . The $\theta_{1}$, that is $\theta_{1}, \theta_{2}, \theta_{3}$ and $\theta_{4}$, are the sizes of the effects that change as years lapse after participation.

Additionally, special attention should be paid for checking whether the effects of medical cost reduction depend on the duration in which the old participated. Provided that the analysis above is to explore the effects of the participation itself, estimating the same effects but in terms of the involvement duration would allow us to figure out the marginal variations depending on the intensity of the project. Model 3 estimates the effects by the following eqn. (3):

$$
\mathrm{Y}_{i j t}=\alpha_{m} \mathrm{PM}_{i j t}+\sum_{k} \beta_{k} \mathrm{X}_{i j t k}+\gamma_{j}+\delta_{t}+\mu_{i}+\varepsilon_{i j t}
$$

Where, $\mathrm{PM}_{i, t}$ represents the number of years of participation for the $i^{\text {th }}$ individual belonging to the $j^{\text {th }}$ cohort at estimated time $t$.

\section{Estimation Results}

\section{Medical cost reduction effects}

Table 3 displays the estimation results of eqn. (1). $\mathrm{X}_{i j t \mathrm{t}}$, the control variables, are presented as in the table and the same variables are included in all other estimations following. As one can see, the participants in the Job Creation Project for the Elderly annually spent KRW 188, 363 less on medical expenditures than the non-participants and it was revealed to be statistically significant. In other words, the estimated results suggest that the elderly could save medical costs by KRW 188,363 by participating in the project.

Also, the absolute sizes of estimates for the year dummies become smaller (The year 2007 is used as reference year), which indicates that medical expenditures tend to become greater as the participating elderly become older. This result confirms the hypothesis that if selection bias exists it would play a role in underestimating effects of medical cost reduction because the comparison group, as mentioned above, is mostly composed of the past observations of individuals in the sample $(95.4 \%$ of the total sample). Given that this research confines the constituents of the sample to those who participated in 2004 to 2007, the fact that medical costs had been reduced even after we controlled the increasing pattern of medical costs as one gets older which might originate from year effect, implies that the estimation results of this paper are highly valid. Therefore, one can ensure that the effect of reduced medical costs for participants in the Job Creation Project would at least not be less than KRW 188, 363.

Table 4 summarizes the results estimated by eqns. (1), (2) and (3). Concerning how the effects of reduced medical cost have been changed after participating in the project, according to the results of the second model, even if the statistical significances are not guaranteed, the first year after participation shows a KRW 75, 611 decrease on average, the second year shows a KRW 95, 229 decrease and the third year and fourth year end up with KRW 21, 791 and KRW 134, 721 reductions, respectively. That is, the effect generally tends to increase each year $\left(\alpha_{1} \rightarrow \alpha_{2} \rightarrow \alpha_{3} \rightarrow \alpha_{4}\right)$ after participation as depicted in Figure 1, which suggests that the effects arose even after participating just once and were augmented each year in general.

On the other hand, regarding the marginal variation of the effects which might be associated with the intensity of the project, the estimation results suggest that, one can save KRW 68, 179 as the duration of participation increases by one year. In other words, if one has participated in the project for four consecutive years, the total accumulated reduced medical costs have amounted to KRW 272, 716.

\section{Effects on the amount of medical care use}

Even if the estimation results of the effect of participating in job creation project on the reduced medical cost are shown to significantly exist, the medical costs of the participants may be reduced not because the participants became healthier, but because they did not have time to go for their medical check-ups during the time of employment in the project. In this context, we further investigated this kind of possibility by estimating the effects on the amounts of medical care use of the participants.

In this paper, the amounts of medical care use are measured by the number of days of hospitalization and that of doctor-visit [18]. The same estimation models, such as eqns. (1) and (3) have been applied in order to evaluate not only the effects on total medical use reduction and but also how the effects have been changed after participating in the project.

Table 5 provides the estimation results of the effects. As can be seen in the table, both effects on the number of days of periods of hospitalization and on the number of doctor-visit do not show any statistical significance, which suggests that the participation in Job Creation Project for the Elderly did not affect the amounts of one's medical service usage. Additionally, the changes of effects on both measurements of medical care use are also insignificant.

Therefore, the participants' significant decrease in medical expenditure with no significant change in the amounts of medical service usage implies that although the participants in the project used the medical services as much as the non-participants, the participants might have less serious diseases, which cost less because their health status have been enhanced after participating in the project. Furthermore, even if both dependent variables are statistically insignificant, the estimated effects on the number of days of hospitalization show relatively larger statistical significance than 


\begin{tabular}{|c|c|c|}
\hline Independent variables & Coefficients & $P$-value \\
\hline Constant & 1513297 & $<0.0001$ \\
\hline Project participation & -188363 & $<0.0001$ \\
\hline Year: 2001 & -837631 & $<0.0001$ \\
\hline Year: 2002 & -786070 & $<0.0001$ \\
\hline Year: 2003 & -690440 & $<0.0001$ \\
\hline Year: 2004 & -561612 & $<0.0001$ \\
\hline Year: 2005 & -385838 & $<0.0001$ \\
\hline Year: 2006 & -162001 & 0.0013 \\
\hline Initial participation year: 2004 & 122818 & 0.0494 \\
\hline Initial participation year: 2005 & 135711 & 0.0068 \\
\hline Initial participation year: 2006 & -1484 & 0.9630 \\
\hline Initial participation year: 2007 & -113021 & 0.0069 \\
\hline Age & 3961 & 0.1730 \\
\hline Number of family members & 40976 & $<0.0001$ \\
\hline Number of chronic diseases & 113093 & $<0.0001$ \\
\hline Personal income & 542 & 0.0579 \\
\hline Family income & -317 & 0.0538 \\
\hline Average monthly expenditures & 1104 & 0.0008 \\
\hline Term of occupation engaged longest & 2046 & 0.0910 \\
\hline Wage of occupation engaged longest & 460 & 0.0220 \\
\hline Region: Dong & 57306 & 0.1822 \\
\hline Region: Myeon & 98154 & 0.0414 \\
\hline Type: Public interest service & -92956 & 0.0061 \\
\hline Type: Instruction service & -21442 & 0.6683 \\
\hline Education level: No education & -42074 & 0.3818 \\
\hline Education level: Below primary school level & -139400 & 0.0380 \\
\hline Education level: Below middle school level & -74997 & 0.0239 \\
\hline Education level: Below high school level & -16345 & 0.6997 \\
\hline Family structure: Single & 62731 & 0.3136 \\
\hline Family structure: Couple & 35920 & 0.5302 \\
\hline Family structure: Living with children & -49025 & 0.4142 \\
\hline Health status: Very bad & 656218 & $<0.0001$ \\
\hline Health status: Bad & -159634 & 0.0002 \\
\hline Health status: Normal & 67980 & 0.0562 \\
\hline Health status: Good & 166056 & 0.0001 \\
\hline No chronic disease & -131582 & 0.0020 \\
\hline Health insurance: Health insurance & -175031 & 0.0001 \\
\hline Health insurance: Medical aid & -190252 & 0.0298 \\
\hline Health insurance: Default in paying premiums & -267136 & 0.0318 \\
\hline Economic status: Very bad & -165179 & 0.0075 \\
\hline Economic status: Bad & -233426 & 0.0497 \\
\hline Economic status: Normal & -212131 & 0.0001 \\
\hline Economic status: Good & -200675 & 0.0005 \\
\hline Satisfaction with the project: Much dissatisfied & 84294 & 0.3057 \\
\hline Satisfaction with the project: Dissatisfied & 138610 & 0.1032 \\
\hline Satisfaction with the project: Normal & -28324 & 0.8715 \\
\hline Satisfaction with the project: Satisfied & 67926 & 0.4216 \\
\hline Industry: Agriculture, forestry and mining & -144729 & 0.0551 \\
\hline Industry: Production and construction & -195575 & 0.0085 \\
\hline Industry: Sales and service & -89656 & 0.1407 \\
\hline Industry: Administration and education & 25648 & 0.6518 \\
\hline Occupation: Executives and professionals & 49778 & 0.4905 \\
\hline Occupation: Mechanics & 2149 & 0.9774 \\
\hline Occupation: Clerks & -9077 & 0.8629 \\
\hline Occupation: Farmers & -109298 & 0.0970 \\
\hline Males & 66578 & 0.0512 \\
\hline Sample size & \multicolumn{2}{|l|}{203} \\
\hline -2 Restricted log likelihood & \multicolumn{2}{|c|}{640643} \\
\hline
\end{tabular}

Table 3: Estimation results of the equation (1).

\begin{tabular}{|c|c|c|}
\hline $\begin{array}{c}\text { Classification } \\
\text { Total effects of medical cost reduction } \\
\text { (Model 1) }\end{array}$ & Estimated effects & P-value \\
\hline $\begin{array}{c}\text { Yearly effects of medical cost reduction } \\
\text { (Model 2) }\end{array}$ & $-1188,363$ & $<0.0001$ \\
\hline First year after participation & $-175,611$ & 0.697 \\
\hline Second year after participation & $-195,229$ & 0.382 \\
\hline Third year after participation & $-121,791$ & 0.630 \\
\hline Fourth year after participation & $-1134,721$ & 0.291 \\
\hline $\begin{array}{c}\text { Marginal effects of medical cost } \\
\text { reduction (Model 3) }\end{array}$ & $-168,179$ & 0.033 \\
\hline
\end{tabular}

Table 4: Medical cost reduction effects: Total, yearly and marginal effects.

\begin{tabular}{|c|c|c|}
\hline Classification & Estimated effects & Statistical significance \\
\hline $\begin{array}{c}\text { Total effects on days of } \\
\text { hospitalization }\end{array}$ & -1.2413 days & 0.123 \\
\hline $\begin{array}{c}\text { Yearly effects on days of } \\
\text { hospitalization }\end{array}$ & -0.7816 days & 0.279 \\
\hline $\begin{array}{c}\text { Total effects on days of } \\
\text { medical treatment }\end{array}$ & 0.2195 days & 0.969 \\
\hline $\begin{array}{c}\text { Yearly effects on days of } \\
\text { medical treatment }\end{array}$ & -0.9405 days & 0.738 \\
\hline
\end{tabular}

Table 5: Effects on periods of medical service usage.

the effects on the number of doctor-visit [19]. Hence, we can confirm that participation in the project does not create a great difference in the possibility of having minor diseases requiring just visit of medical institution but relatively decreases the possibility of having serious diseases requiring hospitalization.

\section{Discussion}

\section{Sensitivity checks}

We find the results in Tables 3-5 are convincing that the health status of the elderly who participate in the job creation project might be enhanced. In this part, several additional analyses are performed for sensitivity checks.

\section{Effects of the reduced medical cost on divided sample according to the characteristics of the participants}

We divided the samples by certain variables and examined the effects on the subsamples, which can provide valuable intuitions associated with the effects of the reduced medical cost of the project. Table 6 presents the estimation results of eqn. (1) in which the effects of participating in the project on total medical costs reduction are supposed to be investigated and one may observe significant effects of reduced medical expenditures in almost all categories.

First of all, in terms of family structure, the reduced medical cost effects are statistically significant for all subgroups but the single group. Especially, those who live with only grandchildren are expected to reduce medical expenditures the most. This result can be interpreted that considering they have responsibility for nurturing their grandchildren and had less opportunity for physical activities to improve their health status before participating in the project, participants living with only their grandchildren generally show better health status and lower medical costs than others after participating in this project.

Next, participants whose education levels are below middle school could save KRW 192, 750, whereas those above high-school level could save KRW 86, 119, which is less than half the figure for the first case. Given that health conditions and education levels have positive correlation in general, the less well educated who are more 
underprivileged are likely to enjoy more outcomes by participating in the project. This interpretation is supported by the following additional analysis: those who participated in the project in order to make money for a living could reduce expenditure by KRW 209, 322, while those who participated for other reasons such as social participation or health improvement could achieve KRW 123, 143 [20]. This confirms that greater effects can be generated for the old who are less privileged.

Lastly, another important subsample is formed by dividing according to the pre-health condition of the participants. It is predictable that the effects of medical cost reduction would differ between the healthy and unhealthy old and the existence of chronic diseases can be a good measure to estimate whether the prediction is valid. The reduced expenditure effects are relatively much larger and more significant for the group having chronic diseases than otherwise. While the former case could save KRW 204, 587 per year on average, the latter could achieve KRW 185, 914 annually. Concerning the fact that a poor economic condition causes a bad health condition in general, we can interpret the results in the same context as the results for subsamples of education level and motivation of participation.

In sum, the facts that the effects of the reduced medical cost were larger and more significant to the underprivileged group whose health status is comparatively poor and has lower socioeconomic status, suggest that the participation in this project could make the participants be healthier than before participating it even with the consideration of sample selectivity.

\section{Effects of the reduced medical cost on divided sample according to type of project}

Table 7 presents the effects of medical cost reduction according to type of project. The salient point in the estimated results is that the effects of public interest service type are about two times greater or even more, than of other types and also the statistical significance is much higher than other cases. The total medical costs of the participants in public interest service were reduced by about KRW 241, 804 compared to non-participants, while participants in instruction service and welfare service reduced by KRW 125, 851 and KRW 100, 344, respectively. The yearly effects for instruction service and welfare service demonstrate an irregular pattern and do not show a clear medical reduction effect, but the yearly effects for public interest service illustrate an evident medical costs reduction effect every year after participation. Finally, the marginal effects, where the effect changes as participation accumulates one year, show similar results; the effects for public interest service, KRW112, 105, are much larger than the effects for instruction service, KRW 30, 121 and the effects for welfare service, KRW 9, 361.

Thus, we must question the reason why public interest service exhibits much larger effects compared to the other types. Comparing public interest service to other types, the distinct difference between the two types concerns the selection process of the participants. Instruction and welfare services both make use of participants' human resources or their specialties and experience; thus, the completion of certain training or education and the degree of one's specialty are crucial factors for selection. On the other hand, as the key criteria for selecting a public interest service, participant's economic situation is considered. For example, if the applicant has no property tax payment history or has only paid small amounts of tax, this is favorable to the applicant in the selection process. Hence, the estimation results suggest that, the elderly who are likely to suffer economic hardship and social isolation show a larger positive health promotion effect by participating in this project. Additionally, this result is highly consistent with the results for

\begin{tabular}{|c|c|c|c|}
\hline \multirow{2}{*}{ Classification } & Subsamples & $\begin{array}{c}\text { Estimated } \\
\text { effects }\end{array}$ & $\begin{array}{c}\text { Statistical } \\
\text { significance }\end{array}$ \\
\hline \multirow{2}{*}{ Sex } & Male & $-1210,819$ & 0.005 \\
\cline { 2 - 4 } Family structure & Female & $-1106,728$ & 0.025 \\
\cline { 2 - 4 } & Single & $-182,289$ & 0.318 \\
\cline { 2 - 4 } & Couple & $-1139,693$ & 0.029 \\
\cline { 2 - 4 } & $\begin{array}{c}\text { Living with children } \\
\text { grandchildren }\end{array}$ & $-1203,265$ & 0.029 \\
\hline \multirow{2}{*}{ Education level } & $\begin{array}{c}\text { Below middle school } \\
\text { level }\end{array}$ & $-1281,446$ & 0.100 \\
\cline { 2 - 4 } & $\begin{array}{c}\text { Above high school } \\
\text { level }\end{array}$ & $-186,119$ & 0.001 \\
\hline \multirow{2}{*}{ Motivation } & Economic motivation & $-1209,322$ & 0.000 \\
\cline { 2 - 4 } & $\begin{array}{c}\text { Non-economic } \\
\text { motivation }\end{array}$ & $-1123,143$ & 0.171 \\
\hline \multirow{2}{*}{ Existence of chronic } & Yes & $-1204,587$ & 0.003 \\
\cline { 2 - 4 } diseases & No & $-1185,914$ & 0.004 \\
\hline
\end{tabular}

Table 6: Medical cost reduction effects divided according to characteristics of the participants.

\begin{tabular}{|c|c|c|c|}
\hline Classification & $\begin{array}{c}\text { Public interest } \\
\text { service }\end{array}$ & $\begin{array}{l}\text { Instruction } \\
\text { service }\end{array}$ & $\begin{array}{l}\text { Welfare } \\
\text { service }\end{array}$ \\
\hline $\begin{array}{l}\text { Total effects of medical cost } \\
\text { reduction } \\
\text { (Model 1) }\end{array}$ & $-1241,804^{* * *}$ & $-\mid 125,851$ & $-1100,344$ \\
\hline $\begin{array}{l}\text { Yearly effects of medical cost } \\
\text { reduction } \\
\text { (Model 2) }\end{array}$ & - & - & - \\
\hline First year after participation & $-122,187^{*}$ & $-111,275$ & 18,203 \\
\hline Second year after participation & $-1162,225^{*}$ & 192,440 & $-153,804$ \\
\hline Third year after participation & $-\mid 181,810^{* *}$ & 1219,269 & 1172,806 \\
\hline Fourth year after participation & $-\mid 179,862$ & $-\mid 102,817$ & $-1170,104$ \\
\hline $\begin{array}{l}\text { Marginal effects of medical cost } \\
\text { reduction } \\
\text { (Model 3) }\end{array}$ & $-1112,105^{* *}$ & $-130,121$ & $-19,361$ \\
\hline
\end{tabular}

Table 7: Medical cost reduction effects according to type of project: Total, yearly and marginal effects.

the subsamples of education level, motivation of the participants and the existence of chronic diseases as discussed in the previous section.

Therefore, we can conclude that a large part of the effects of reduced medical expenditure is derived from the improved health of participants with economic hardship and poor health status, which suggests that the estimation results on total sample above might be robust. Furthermore, the present rule of policy that distributes the rights to participate in the Job Creation Project for the elderly who are more in need and unwell, seems to be desirable in terms of improving the health status of the underprivileged old.

\section{Conclusion}

The positive causal relationship between labor and health status is a widely accepted concept that it may seem unnecessary to investigate. This paper has found that the old participating in the project reduced their medical costs annually by KRW 188, 363 (about USD 188). Such effects are shown to be greater for those who were poorer and less healthy.

These results are more reliable than those of previous studies in that the empirical model adopted in this paper, excluded probabilities of Healthy Hire Effect (HHE) or Healthy Survivor Effect (HSE) by applying not only appropriate research design but also the unique 
feature of choosing comparison group. However, we must be careful for interpreting the reduced medical costs as the participants' improved health. As introduced above, when we examined the effects of the project on amounts of medical care use, there was no great difference between participants and non-participants. Therefore, the decrease in medical expenditure with no change in the amounts of medical service use implies that although the participants in the project used the medical services as much as the non-participants, participants might have less serious diseases, which cost less because the participants' health status becomes improved by participating in this project.

Notwithstanding, in order to explore these concepts further, we additionally examined the change of performing health-related behavior of the participants after participation. The separate survey we used contained the information on how the participants' health promotion behaviors have been changed after participating in the project. The relevant behaviors include five areas: smoking, alcohol consumption, weight management, regular exercise and ordinary activities - and each area is measured on a five-point scale depending on how big the changes of health promotion behavior were after participating in this project. If the participants had exerted to enhance their health status through changing their health promotion behaviors, the effects of the reduced medical cost might be interpreted that the participant become healthier than before.

The estimation results suggest that, although smoking and drinking behavior did not show much change, since these behaviors seem to be highly addictive, which is hard to quit or change, the other behaviors were found to show greater changes for those involved in the project. Therefore, we can conclude that the medical cost reduction found in the study indicates that the participants promoted their health by changing their health-related behavior after participating in the project.

In term of the policy perspective, the job creation project might be supported not only by its provision of income security with the elderly, but also by its chance of enhancing health status of the participants, which might cause the burden of their paying medical cost to be reduced and also improve the sustainability of public health insurance system of Korea.

\section{Acknowledgement}

This work was supported by Korea University research fund (FRG research) K1720471.

\section{References}

1. Korea Presidential Committee on Ageing and Future Society (2004) National Strategy for Low Fertility-Aged Society (in Korean).
2. Ross CE, Mirowsky J (1995) Does employment affect health? J Health Soc Behav 36: 230-243.

3. Li CY, Sung FC (1999) A review of the healthy worker effect in occupationa epidemiology. Occup Med 49: 225-229.

4. Baillargeon J, Wilkinson GS (1999) Characteristics of the health survivor effect among male and female Hanford workers. Amr J Indus Med 35: 343-347.

5. Link BG, Phelan J (1995) Social conditions as fundamental causes of disease J Health Social Behavior 35: 80-94.

6. Minkler M (1981) Research on the health effects of retirement: An uncertain legacy. J Health Soc Behav 22: 117-130.

7. Bloom HS, Michalopoulos C, Hill CJ, Lei Y (2002) Can Non-enxperimental Comparison Group Methods Match the Findings from a Random Assignment Evaluation of Mandatory Welfare-to-Work Programs? MDRC Working Papers on Research Methodology. New York, NY: Manpower Demonstration Research Corporation.

8. Lee SW (2001) Evaluating active labor market programs using randomized experiments. The Korean J Policy Studies 35: 91-107.

9. Bloom HS (2003) Using "Short" interrupted time-series analysis to measure the impacts of whole-school reforms: With Applications to a study of accelerated schools. Evaluation Rev 27: 3-49

10. Schaie KW (1965) A general model for the study of developmental problems Psychol Bulletin 64: 92-107.

11. Jenkins SR, Maslach C (1994) Psychological health and involvement in interpersonally demanding occupations: A longitudinal perspective. J Organizational Behav 15: 101-127.

12. Lawrence $\mathrm{JH}$, Blackburn RT (1988) Age as a predictor of faculty productivity. $J$ Higher Edu 59: 22-38.

13. Clayton RR, Bokemeier JL (1980) Premarital sex in the seventies. J Marriage Family: 759-775.

14. Anderson ER (1993) Analyzing change in short-term longitudinal research using cohort-sequential designs. J Consulting Clin Psychol 61: 929-940.

15. Cohen J (1988) Statistical Power Analysis for the Behavioral Sciences. $2^{\text {nd }}$ edn Hillsdale, NJ: Lawrence Erlbaum.

16. Blalock AB (1990) Evaluating programs. In: Ann Bonar Blalock (ed) Evaluating Social Programs at the State and Local Level: The JTPA Evaluation Design Project. Kalamzoo, MI: WE Upjohn Institute, pp: 3-40.

17. Fraker T, Maynard R (1987) The adequacy of comparison group design fo evaluations of employment-related programs. J Human Resource 22: 194-227.

18. LaLonde $\mathrm{R}$ (1986) Evaluating the econometric evaluations of training programs with experimental data. The Amr Econom Rev 76: 604-620.

19. Manski CF, Garfinkel I (1992) Introduction. In: Charles F, Manski CF, Grafinke I (eds) Evaluating Welfare and Training Programs, 1-22. Cambridge, MA Harvard University Press.

20. Orr LL (1999) Social Experiments. Thousand Oaks, California: SAGE Publications, Inc. 